ABDIMAS: Jurnal Pengabdian Masyarakat Universitas Merdeka Malang
Vol.7(1) February 2022, 149-157
i-ISSN: 2721-138X e-ISSN: 2548-7159
ittp://jurnal.unmer.ac.id/index.php/jpkm

\title{
The application of sustainable organic farming with hydroponic system for farmers in Gending Village
}

\section{Penerapan pertanian organik secara berkelanjutan dengan sistem hidroponik bagi petani di Desa Gending}

\author{
Ihyak Mustofa', Mas Ahmad Baihaqi², Zico Awalatul Badar ${ }^{3}$ \\ ${ }^{7}$ Departemen Sastra Inggris, Fakultas Sastra dan Filsafat, ${ }^{2}$ Departemen Teknik Elektro, Fakultas Teknik, \\ ${ }^{3}$ Departemen Akuntansi, Fakultas Ekonomi, Universitas Panca Marga Probolinggo \\ Jl. Yos Sudarso, Probolinggo, 67216, Indonesia
}

\begin{abstract}
ARTICLE INFO:
Received: 2021-09-04 Revised: 2021-10-12

Accepted: 2021-12-04

Keywords:

Agriculture, Farmer, Hydroponics
\end{abstract}

\begin{abstract}
Gending Village is a village located in Gending District, Probolinggo Regency which is used as one of the economic centers in Probolinggo Regency. This causes 60 percent of the land for cultivation to be converted to industrial areas. As written in detik.com Daily on Wednesday, Jan 16, 2019. Hydroponics is a system for cultivating plants without using soil media but using water media that contains minerals and nutrients. The purpose of the socialization activity on the application of organic farming with hydroponic methods for farmers in Gending Village is to increase the knowledge of farmers in Gending Village regarding alternative solutions to the problem of increasingly narrow agricultural land. The implementation method in this activity is by direct socialization. The socialization about hydroponics was carried out with the help of PowerPoint slides and videos of hydroponic making practices that had been previously made by the KKN Parading team. After that, it was followed by a discussion and question and answer session with the farmers in Gending village regarding the material that had been delivered. The result of this activity is hydroponic equipment and plants which are distributed to farmers who take part in socialization activities and distributed to residents.
\end{abstract}

(c) 2022 Abdimas: Jurnal Pengabdian Masyarakat Universitas Merdeka Malang This is an open access article distributed under the CC BY-SA 4.0 license (https://creativecommons.org/licenses/by-sa/4.0/)

How to cite: Mustofa, I., Baihaqi, M. A., \& Badar, Z. A. (2022). The application of sustainable organic farming with hydroponic system for farmers in Gending Village. Abdimas: Jurnal Pengabdian Masyarakat Universitas Merdeka Malang, 7(1), 149-157. https://doi.org/10.26905/abdimas.v7i1.6334

\section{PENDAHULUAN}

Indonesia merupakan negara agraris yang sebagian besar penduduknya bermata pencaharian sebagai petani. Di Indonesia kegiatan bercocok tanam pada umumnya dilakukan dengan menggunakan media tanah. Menurut Haidiputri (2021), ketersediaan lahan untuk budidaya semakin berkurang seiring meningkatnya kegiatan industri, pertanian, dan pemukiman. Sehingga hal tersebut menuntut para petani di Indonesia untuk tetap produktif ditengah maraknya pembangunan yang membuat lahan untuk bercocok tanam semakin sempit. 
ABDIMAS: Jurnal Pengabdian Masyarakat Universitas Merdeka Malang

Volume 7, No 1, February 2022: 149-157

Desa Gending merupakan salah satu desa yang terletak di Kecamatan Gending Kabupaten Probolinggo yang dijadikan sebagai pusat perekoniman di Kabupaten Probolinggo. Hal tersebut dibuktikan dengan banyaknya pabrik-pabrik industri serta fasilitas-fasilitas umum yang dibangun di desa tersebut sehingga menyebabkan lahan pertanian di Kabupaten Probolinggo sudah dialihfungsikan lahan untuk bercocok tanam banyak yang dialihfungsikan. Hal ini seperti yang ditulis Rofiq (2019) melalui detik.com bahwa 60 Persen lahan jagung di Kabupaten Probolinggo sudah dialihfungsikan. Untuk mengatasi permasalahan tersebut para petani di Desa Gending dituntut untuk mencari solusi alternatif agar tetap dapat memenuhi kebutuhan pangannya seiring dengan pertumbuhan penduduk yang semakin meningkat seiring dengan ketersediaan lahan pertanian yang semakin sempit.

Salah satu metode alternatif berococok yang bisa diterapkan petani di Desa Gending di tengah lahan pertanian yang semakin sempit adalah metode hidroponik. Hidroponik merupakan salah satu metode budidaya tanaman pertanian tanpa menggunakan media tanah melainkan menggunakan media seperti sekam padi, kapas, arang, rockwool, larutan mineral yang mengandung nutrisi, dan lain lain. Dengan menerapkan metode ini maka para petani di Desa Gending tidak perlu memikirkan masalah kekurangan lahan untuk media tanam karena metode ini bisa diterapkan dimana saja seperti pada jeriken bekas, botol bekas, pipa PVC yang nantinya dapat diletakkan di lahan yang sempit.

Untuk memaksimalkan solusi tersebut maka mahasiswa KKN UPM Probolinggo kelompok Parading (Pajarakan-Gending) mengadakan kegiatan bimbingan teknis kepada para petani Desa Gending. Pelaksanaan bimbingan teknis dilakukan dengan cara sosialisasi kepada para petani di Desa Gending mengenai "Penerapan Pertanian Organik secara Berkelanjutan dengan Metode Hidroponik". Kegiatan ini merupakan salah satu bentuk implementasi program pengabdian kepada masyarakat. Kemudian, program pengabdian masyarakat ini bertujuan untuk membantu petani memanfaatkan lahan sempit melalui metode hidroponik.

\section{METODE}

\section{Waktu, Tempat, Sasaran, dan Mitra Penelitian}

Kegiatan pengabdian masyarakat ini dilakukan pada tanggal 27-29 Agustus 2021. Tempat atau lokasi pengabdian masyarakat ini berada di Desa Gending, Kecamatan Gending, Kabupaten Probolinggo. Sasaran program pengabdian masyarakat ini adalah petani-petani yang tinggal di daerah Desa Gending, Kecamatan Gending, Kabupaten Probolinggo, Provinsi Jawa Timur. Program pengabdian masyarakat ini bekerjasama dengan pihak Kecamatan Gending dan seluruh perangkat Desa Gending, Kabupaten Probolinggo.

\section{Metode Pelaksanaan}

Metode yang dilakukan dalam melaksanakan kegiatan ini yaitu dengan cara sosialisasi secara langsung, berdiskusi, dan melakukan tanya jawab kepada para petani di Desa Gending mengenai pertanian organik secara berkelanjutan dengan metode hidroponik baik mulai dari pengertian, manfaat, dan kelebihannya agar pengetahuan dan wawasan petani di Desa Gending bertambah dan dapat mengimplementasikannya dalam kehidupan sehari hari.

Sosialisasi tentang hidroponik ini dilakukan dengan bantuan media berupa slide Power Point dan juga dengan menayangkan video praktik pembuatan hidroponik yang sudah dibuat sebelumnya oleh tim KKN Parading. Kegiatan pengabdian masyarakat ini dilakukan oleh tim kelompok terbatas yang

terdiri dari mahasiswa Fakultas Pertanian dan Fakultas Ekonomi Universitas Panca Marga Probolinggo dengan audien adalah 10 orang petani di Desa Gending namun petani yang hadir berjumlah 7 orang dan tetap menerapkan protokol kesehatan. 
Hidroponik berasal dari kata Yunani 'Hydro' yang berarti air dan 'Ponos' yang berarti mengerjakan. Menurut Purbajanti et al. (2017), menyatakan: "Hidroponik dapat diartikan sebagai cara budidaya tanaman dengan menggunakan medium air". Sedangkan dalam Swastika et al. (2018) menyatakan: "Hidroponik yaitu sistem budidaya menggunakan air yang mengandung nutrisi dan mineral tanpa tanah". Hidroponik adalah salah satu metode budidaya tanaman tanpa menggunakan media tanah, melainkan menggunakan media air yang mengandung mineral dan nutrisi.

Konsep atau cara kerja metode hidroponik sendiri yaitu dengan cara menumbuhkan tanaman tanpa menggunakan media tanah melainkan menggantinya dengan media lain seperti sekam padi, kapas, arang, rockwool, dan lain lain sebagai pijakan akar sehingga dapat memudahkan akar tanaman dalam menyerap larutan mineral dan nutrisi dalam air. Kelebihan metode hidroponik adalah: (1) Keberhasilan pertumbuhan dan produksi tanaman lebih terjamin; (2) Pertumbuhan tanaman lebih cepat; (3) Perawatannya lebih mudah, praktis, efisien, dan tidak perlu banyak tenaga karena metode kerja yang sudah terstandarisasi; (4) Pemakaian pupuk dan air menjadi lebih hemat; (5) Kebebasan tanaman dari gangguan penyakit dan hama lebih terjamin; (6) Hasil panen yang lebih continue; (7) Jika tanaman ada yang mati, proses penggantian dengan tanaman yang baru lebih menjadi lebih mudah; (8) Kualitas tanaman yang dihasilkan dari metode hidroponik lebih sempurna dan bersih; (9) Tanaman yang tidak cocok dengan lingkungan tertentu akan tetap tumbuh; (10) Terhindar dari risiko ketergantungan dengan kondisi alam; (11) Tidak memerlukan ruang dan tempat yang begitu luas sehingga dapat dilakukan ditempat yang sempit seperti atap, dinding, balkon rumah, dapur dan lain lain.

Adapun kekurangan metode hidroponik adalah: (1) Modal investasi awal yang cukup tinggi; (2) Memerlukan pengalaman dan keahlian yang tinggi; (3) Membutuhkan takaran nutrisi dengan formulasi tertentu; (4) Cukup sulit dalam hal perawatan perangkat serta ketersediaannya.

\section{Teknik-teknik Hidroponik \\ Teknik Wick}

Teknik ini merupakan teknik yang paling mudah dan sederhana. Teknik ini dilakukan dengan cara memanfaatkan sumbu atau perantara untuk menghubungkan akar tanaman dengan larutan nutrisi karena dalam teknik ini akar tanaman dan air tidak bersentuhan secara langsung (Swastika et al., 2018). Ferdiansyah \& Aspani (2015) mengemukakan bahwa wick system adalah metode hidroponik yang menggunakan perantara sumbu antara nutrisi dan media tanam.

\section{NFT (Nutrient Film Technique)}

Teknik ini merupakan teknik hidroponik dengan cara mengalirkan nutrisi secara terus menerus menggunakan pompa air agar larutan nutrisi dapat tersirkulasi sehingga tanaman memperoleh air, oksigen, dan nutrisi yang cukup dan dapat tumbuh dengan baik (Swastika et al., 2018).

\section{Teknik Rakit Apung (Deep Water Culture)}

Teknik ini merupakan salah satu teknik hidroponik dengan cara membuat tanaman mengapung sehingga akar tanaman bersentuhan langsung pada larutan nutrisi dan pompa yang menjaga agar oksigen dalam larutan tetap terjaga (Swastika et al., 2018). Permatasari (2012) menunjukan sistem rakit apung dirakit dengan cara yang cukup sederhana sehingga berpotensi untuk kembali dikembangkan sebagai media praktikum di sekolah dengan ukuran yang lebih sederhana dan disesuaikan dengan kebutuhan 
ABDIMAS: Jurnal Pengabdian Masyarakat Universitas Merdeka Malang

Volume 7, No 1, February 2022: 149-157

\section{Teknik Drip}

Teknik ini disebut juga teknik fertigasi yang dilakukan dengan cara memberikan air dan larutan nutrisi secara bersamaan dan perlahan langsung pada akar tanaman dengan tujuan menghemat air dan nutrisi akan diberikan (Swastika et al., 2018)
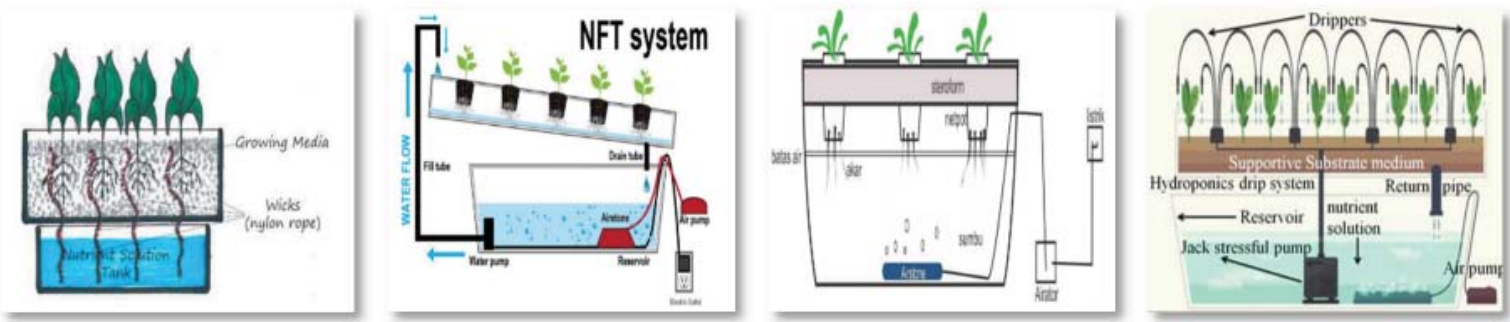

Gambar 1. Hidroponik dengan Teknik Wick Gambar 2. Hidroponik dengan NFT

Gambar 3. Hidroponik dengan Teknik Rakit Apung

Gambar 4. Hidroponik dengan Teknik Drip

\section{Media Tanam}

Media tanam merupakan komponen utama dalam proses budidaya dan harus disesuaikan dengan jenis tanaman yang ingin ditanam (Amilah, 2012). Pada metode hidroponik terdapat dua media tanam yang bisa digunakan yaitu media organik dan media anorganik. Dalimoenthe (2013) menjelaskan bahwa media tanam yang termasuk dalam kategori bahan organik umumnya berasal dari komponen organisme hidup, misalnya bagian dari tanaman seperti daun, batang, bunga, buah, atau kulit kayu. Untuk media organik menggunakan sekam, arang, sabut kelapa, serbuk gergaji, gambut, dan lain lain. Magfiranur (2018) menjelaskan bahwa media tanam anorganik merupakan media tanam yang menggunakan bahan yang memiliki kandungan unsur mineral tinggi dan berasal dari proses pelapukan yang ada terdapat di inti bumi. Sedangkan untuk media anorganik kita bisa menggunakan rockwool, batu bata, perlit, clay granular, gravel, dan lain lain.

Kegiatan ini dilaksanakan dengan dua tahap, tahan pertama yaitu persiapan yang mana pada tahap ini tim kelompok terbatas KKN Parading membuat video tentang tata cara pembuatan hidroponik untuk nantinya ditayangkan kepada para petani yang hadir dalam kegiatan sosialisasi. Dalam pembuatan video tersebut ada beberapa alat dan bahan yang perlu disiapkan yaitu: (1) Alat terdiri dari pisau dan gunting; (2) Bahan terdiri dari rockwool, benih tanaman, kain flanel, jeriken bekas, air, wadah pembibitan, gelas plastik bekas, dan nutrisi AB Mix.
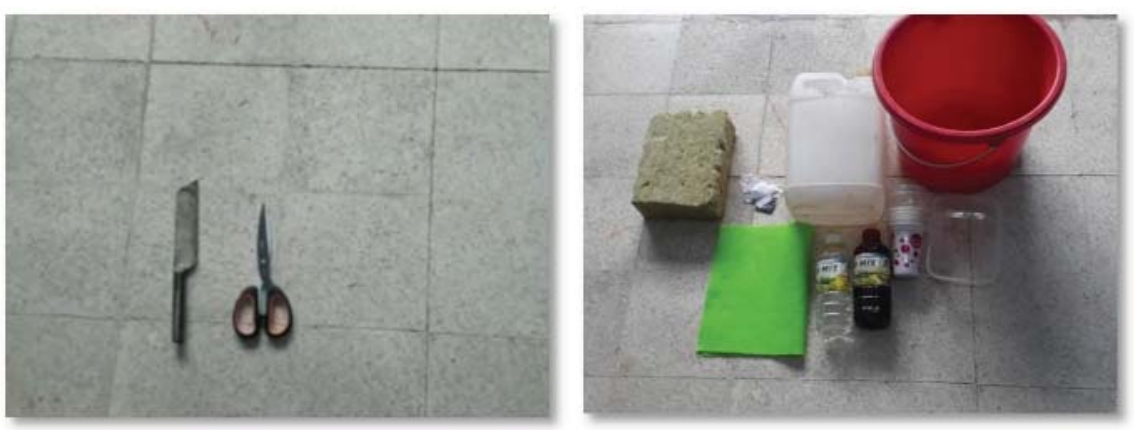

Gambar 5. Alat

Gambar 6. Bahan 


\section{The application of sustainable organic farming with hydroponic system for farmers in Gending Village}

Ihyak Mustofa, Mas Ahmad Baihaqi, Zico Awalatul Badar

\section{Jenis Tanaman}

Jenis tanaman hidroponik adalah jenis tanaman yang tidak memerlukan perawatan khusus, mudah dalam merakit, portabel (dapat dipindahkan), dan cocok di lahan terbatas (Diah, 2015). Jenis tanaman yang dapat dibudidayakan dengan metode hidroponik bermacam-macam mulai dari sayursayuran seperti sawi, kangkung, brokoli, pakchoi, selada, tomat, cabai, dan lain lain. Sedangkan untuk jenis buah-buahan yang dapat dibudidaya dengan metode hidroponik yaitu mentimun, strawberry, semangka, paprika, melon, tomat, dan lain lain. Tidak hanya sayur-sayuran dan buah-buahan tetapi beberapa tanaman hias juga bisa dibudidayakan dengan metode hidroponik seperti tanaman kaktus, krisan, anggrek, kaladium, dan lain lain. Berdasarkan penelitian Paputungan (2014), pertumbuhan sawi hijau pada berbagai media tanam hidroponik menunjukkan bahwa pada umur 2 MST (minggu setelah tanam) pertumbuhan tinggi tanaman sawi yang tertinggi pada perlakuan media sabut kelapa dengan rerata mencapai $16,30 \mathrm{~cm}$.

Tabel 1. Jadwal kegiatan

\begin{tabular}{ll}
\hline Hari ke-1 & \\
Aktivitas & - Pemaparan metode pelaksanaan \\
& - Pengenalan peralatan yang akan digunakan \\
& - Pengenalan contoh karya yang akan dibuat pada pelaksanaan program pengabdian \\
Tujuan & - Pengenalan program-program pengabdian dan tim pelaksana \\
& - Menjelaskan peralatan yang digunakan dalam pelaksanaan program pengabdian dan contoh karya \\
& dalam program pengabdian masyarakat \\
Hari ke-2 & \\
Aktivitas & - Pemilihan bahan \\
& - Pembersihan pada bahan yang akan digunakan \\
& - Pembuatan rancangan produk \\
& - Pembuatan pola sesuai gambar yang telah dibuat \\
Tujuan & - Memberikan wawasan kepada peserta dan menghasilkan produk \\
& - Membersihkan kotoran pada bahan yang telah dipilah untuk dimanfaatkan \\
Hari ke-3 & Menyesuaikan hasil dengan produk yang dibuat \\
Aktivitas & \\
& - Pembagian souvenir kepada peserta \\
& - Memberikan evaluasi hasil \\
& - Penutup \\
Tujuan & - Memberikan kenang-kenangan dan tanda terima kasih kepada peserta dan mitra \\
& - Evaluasi produk para peserta yang disertakan saat acara penutup
\end{tabular}

\section{HASIL DAN PEMBAHASAN}

Langkah-langkah pembuatan hidroponik dibagi menjadi tiga yaitu, tahap pembibitan (semai), tahap pembuatan nutrisi, dan tahap pembuatan media hidroponik. Tahap-tahap dalam pembibitan (semai) adalah sebagai berikut: (1) Siapkan pisau, gunting, rockwool, wadah pembibitan, dan air; (2) Potong rockwool menjadi dadu dengan ukuran $2 \times 2 \mathrm{~cm}$ kemudian tusuk bagian tengah menggunakan gunting sekitar 0,5 cm (sebagai media semai); (3) Letakkan rockwool kedalam wadah pembibitan lalu basahi dengan air; (4) Letakkan 1 sampai 2 benih kedalam lubang rockwool; (5) Simpan di tempat yang tidak terpapar cahaya matahari secara langsung hingga benih berkecambah (1-2 minggu). Selanjutnya tahap pembuatan nutrisi adalah sebagai berikut: (1) Siapkan air sebanyak 1 liter dan nutrisi hidroponik $A$ dan B; (2) Campurkan nutrisi A dan B dengan takaran 1 tutup botol nutrisi A dan B kedalam 1 liter air dan aduk sampai merata. Terakhir tahap pembuatan media hidroponik sebagai berikut: (1) Siapkan pisau, 
ABDIMAS: Jurnal Pengabdian Masyarakat Universitas Merdeka Malang

Volume 7, No 1, February 2022: 149-157

gunting, jeriken bekas, 4 gelas plastik, kain flanel, dan benih yang sudah tumbuh; (2) Lubangi jeriken sebanyak 4 lubang dengan ukuran menyesuaikan gelas plastik; (3) Gunting kain flanel dengan ukuran $2 \mathrm{x}$ $15 \mathrm{~cm}$ (sebagai sumbu); (4) Siapkan 4 gelas plastik kemudian lubangi bagian samping gelas plastik untuk memasukkan sumbu dari kain flanel; (5) Letakkan benih beserta rockwool ke dalam gelas plastik yang sudah diberi sumbu; (6) Isi jeriken bekas yang sudah dilubagi dengan air yang sudah dicampur nutrisi; (7) Letakkan gelas plastik yang sudah berisi benih tanaman ke 4 lubang jeriken tersebut; (8) Langkah terakhir letakkan media hidroponik tersebut di tempat yang terpapar cahaya matahari secara langsung sampai siap panen.

Tahap demi tahap di atas telah direkam menggunakan ponsel. Lalu hasil rekaman tersebut diunggah di youtube dengan tautan https://youtu.be/VIU2xBd-IIU. Setelah pembuatan video tentang tata cara pembuatan hidroponik, kegiatan selanjutnya yaitu pelaksanaan tahap kedua berupa kegiatan sosialisasi kepada petani. Kegiatan sosialisasi tersebut terbagi menjadi 2 sesi, yaitu penyampaian materi dan sesi tanya jawab yang dihadiri oleh 7 orang petani di Desa Gending dan berjalan dengan lancar dan cukup efektif. Hal tersebut dibuktikan dengan antusiasme dan respon positif para petani terkait materi yang disampaikan.

Dengan adanya kegiatan sosialisasi tentang penerapan pertanian organik secara berkelanjutan dengan metode hidroponik ini, diharapkan dapat menambah pengetahuan dan wawasan bagi para petani. Selain itu, metode ini dapat menjadi solusi alternatif bagi para petani sehingga para petani tetap bisa produktif. Jadi, petani tidak perlu cemas akan lahan pertanian yang semakin sempit ditengah maraknya pembangunan.
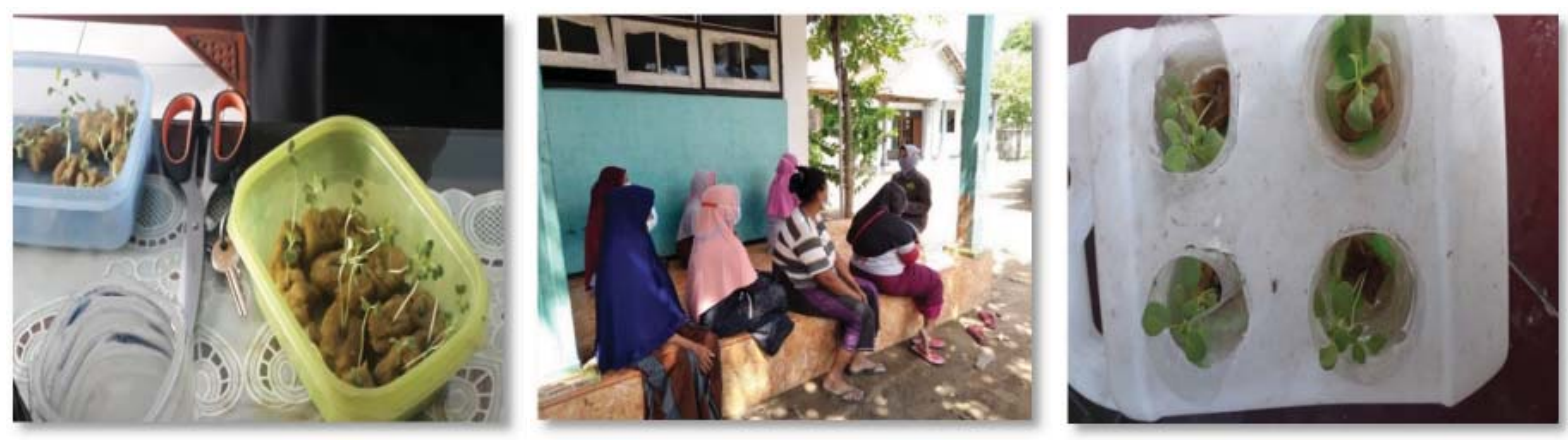

Gambar 7. Benih yang didiamkan selama 1-2 minggu

Gambar 8. Sosialiasasi tentang hidroponik kepada para petani

Gambar 9. Tanaman hidroponik

Kegiatan ini bertujuan untuk membantu petani untuk memanfaatkan lahan yang sempit menjadi lahan produktif melalui metode hidroponik. Hasil yang dicapai tidak ada pertentangan atau ketidaksesuaian. Hal ini karena hasil yang dicapai menunjukkan hasil yang sama yaitu menjadikan sistem hidroponik sebagai solusi alternatif bagi masyarakat yang ingin bercocok tanam namun memiliki lahan yang sempit. Lalu petani juga mendapatkan perangkat hidroponik beserta tanamannya untuk dimanfaatkan di lingkungannya.

Ada beberapa penelitian terdahulu tentang hidroponik, salah satunya jurnal yang dibuat oleh Mulasari (2018) dengan judul "Penerapan Teknologi Tepat Guna (Penanam Hidroponik Menggunakan Media Tanam) bagi Masyarakat Sosrowijayan Yogyakarta". Menurut Mulasari (2018), tujuan penanaman tersebut adalah untuk mengurangi masalah sampah dan menambah wawasan warga sekitar tentang cara pemanfaatan barang bekas menggunakan hidroponik. Metode pelaksanaan yang dilakukan dalam 


\section{The application of sustainable organic farming with hydroponic system for farmers in Gending Village Ihyak Mustofa, Mas Ahmad Baihaqi, Zico Awalatul Badar}

kegiatan pengabdian masyarakat ini yaitu dengan cara memberikan ceramah mengenai hidroponik, melakukan diskusi dan tanya jawab, dan melakukan praktik kegiatan bercocok tanam secara hidroponik. Sehingga diharapkan pengetahuan warga mengenai hidroponik, serta dapat meningkatkan kesadaran masyarakat untuk memanfaatkan barang bekas sebagai upaya dalam mengurangi keberadaan sampah plastik di kehidupan masyarakat.

Berikutnya, Singgih et al. (2019) menjelaskan bahwa kegiatan pengabdian masyarakat yang dilakukan dengan tujuan agar lahan warga yang tak digunakan bisa digunakan secara maksimal untuk media tanam hidroponik. Metode pelaksanaan yang dilakukan dalam kegiatan pengabdian masyarakat ini yaitu dengan cara melakukan penyuluhan sistem budidaya tanaman hidroponik NFT serta tanya jawab terkait materi yang dibahas. Dengan adanya kegiatan ini diharapkan warga Desa Mojopetung mampu membuat tindak lanjut pengadaan alat dan bahan budidaya hidroponik, dapat membuat produk hidroponik yang dapat dimanfaatkan dalam kehidupan sehari-hari, masyarakat juga diharapkan dapat mengerti tentang bagaimana proses perawatan tanaman budidaya hidroponik, dan bisa menjadi alternatif budidaya atau teknik bertanam secara hidroponik karena bisa dilakukan oleh orang yang tidak memiliki lahan yang cukup.

Lalu, jurnalyang dibuat oleh Roidah (2014) denganjudul “Pemanfaatan Lahan dengan Menggunakan Sistem Hidroponik". Menurut Roidah (2014) pembuatan dan pemanfaatan sistem pertanian hidroponik di lahan yang sempit dibuat dengan tujuan agar teknologi budidaya pertanian dengan sistem hidroponik dapat dijadikan salah satu alternatif bagi masyarakat yang mempunyai lahan terbatas atau pekarangan, sehingga dapat dijadikan sebagai sumber penghasilan yang memadai.

Berdasarkan ketiga penelitian di atas dapat ditarik gap penelitian yaitu: (1) Jurnal Mulasari (2018) menjelaskan bahwa untuk wadah tanaman hidropik menggunakan wadah bekas dari botol plastik yang mudah rusak karena materialnya terbuat dari plastik yang tipis. Dalam jurnal ini, wadah tanaman menggunakan jeriken bekas yang lebih tahan lama dan tidak mudah rusak dibandingkan dengan botol plastik; (2) Jurnal berikutnya Singgih et al. (2019), membahas tentang pembuatan hidroponik dengan sistem NFT, sedangkan dalam jurnal ini untuk untuk pembuatan hidropik menggunakan Sistem Wick yang mana metode tersebut merupakan metode pembuatan hidroponik yang paling sederhana dibandingkan metode metode lainnya; (3) Jurnal ketiga, Roidah (2014), membahas tentang tata cara pembuatan hidroponik dengan objek sasarannya yaitu masyatakat secara umum, sedangkan dalam jurnal ini untuk objek sasaran yang dituju lebih spesifik yaitu petani Desa Gending.

Implikasi jurnal ini dengan referensi sebelumnya adalah untuk membuat perangkat hidroponik dengan Teknik Wick membutuhkan alat yang sederhana seperti botol bekas, jeriken bekas, kaleng bekas, dan lain lain. Alat alat tersebut merupakan alat alat yang mudah dicari dan tidak memerlukan biaya yang banyak untuk mendapatkannya sehingga cocok untuk diterapkan bagi para pemula yang ingin bercocok tanam dengan sistem hidroponik

Berikutnya, teknik ini merupakan teknik yang paling sederhana dibandingkan teknik-teknik yang lain. Oleh karena itu, teknik ini merupakan teknik yang paling mudah untuk diterapkan dan tidak memerlukan banyak tenaga, waktu, dan biaya untuk membuatnya.

Manfaat dari hasil program pengabdian masyarakat ini yaitu para petani dapat memanfaatkan lahan yang sempit menjadi lahan yang produktif dengan cara menerapkan metode hidroponik. Dari segi ekonomi penerapan metode hidroponik ini berdampak terhadap penghasilan para petani di Desa Gending. Perekonomian keluarga menjadi meningkat karena apat menghemat biaya sehari hari dan dapat menjual hasil dari hidroponik di pasar. Dari segi kesehatan penerapan hidroponik memberikan hasil panen yang lebih sehat dan bersih karena bebas dari penyakit dan hama. 
ABDIMAS: Jurnal Pengabdian Masyarakat Universitas Merdeka Malang

Volume 7, No 1, February 2022: 149-157

\section{SIMPULAN DAN SARAN}

Kegiatan pengabdian masyarakat ini sesuai dengan tujuan pengabdian, yaitu untuk membantu para petani di Desa gending untuk lebih produktif dengan cara memanfaatkan lahan yang sempit menjadi lahan produktif melalui metode hidroponik. Sistem hidroponik merupakan salah satu solusi alternatif bagi masyarakat yang memiliki permasalahan terkait lahan pertanian yang semakin sempit di tengah maraknya pembangunan karena sistem ini dapat diterapkan dimana saja dan kapan saja. Dari kegiatan yang telah dilaksanakan, hasil yang dicapai tidak ada pertentangan atau ketidaksesuaian. Hal ini karena hasil yang dicapai menunjukkan hasil yang selaras yaitu menjadikan sistem hidroponik sebagai solusi alternatif bagi masyarakat yang ingin bercocok tanam namun memiliki lahan yang sempit.

Kegiatan ini terbatas pada petani di Desa Gending, Kecamatan Gending, Kabupaten Probolinggo. Hal ini membuat kegiatan ini kurang meluas. Adapun saran yang bisa diterapkan bagi pengabdi selanjutnya adalah peserta tidak dibatasi dalam satu desa agar dampak dari program ini bisa dirasakan oleh petani di daerah lain. Program ini hanya terbatas pada penerapan metode hidroponik dengan Teknik Wick. Adapun saran yang dapat kami sampaikan kepada peneliti peneliti selanjutnya agar mencoba mengaplikasikan teknik hidroponik lainnya. Kegiatan ini terbatas untuk para petani. Alangkah lebih baiknya apabila program ini bisa diterapkan oleh masyarakat di setiap keluarga. Selain untuk menambah penghasilan, bisa juga untuk menghemat pengeluaran sehari-hari.

\section{DAFTAR PUSTAKA}

Amilah, S. A. (2012). Penggunaan berbagai media tanam terhadap pertumbuhan dan perkembangan tanaman brokoli (Brassica oleracea varitalica) dan baby kailan (Brassica oleracea var. Alboglabra baley). Wahana: Tridarma Perguruan Tinggi, 59(2), 10-16.

https://doi.org/10.36456/wahana.v59i2.1216

Dalimoenthe, S. L. (2013). Pengaruh media tanam organik terhadap pertumbuhan dan perakaran pada fase awal benih teh di pembibitan. Jurnal Penelitian Teh dan Kina, 16(1), 1-11.

Diah, A. S. (2015). Hidroponik wick system. Jakarta: Agromedia Pustaka.

Ferdiansyah, R., \& Aspani, A. (2015). Hidroponik sistem wick. Teknik Presenstasi STMIK Banjarbaru.

Haidiputri, T. A., \& Elmas, M. S. H. (2021). Pengenalan BUDIKDAMBER (Budidaya Ikan Dalam Ember) untuk ketahanan pangan di Kecamatan Dringu Kabupaten Probolinggo. Jurnal Abdi Panca Mara, 2(1). https://doi.org/10.51747/abdipancamara.v2i1.737

Magfiranur, A., (2018). Macam-macam media tanam. Cybex.

Mulasari, S. A. (2018). Penerapan teknologi tepat guna (penanam hidroponik menggunakan media tanam) bagi masyarakat Sosrowijayan Yogyakarta. Jurnal Pemberdayaan: Publikasi Hasil Pengabdian Kepada Masyarakat, 2(3), 425-430. https://doi.org/10.12928/jp.v2i3.418

Paputungan, I. R. (2014). Intensitas serangan penyakit antraknosa pada 3 varietas tanaman tomat (Solanum lycopersicum L.) [Skripsi, Universitas Negeri Gorontalo]. UNG Repository.

Permatasari, R. (2012). Efektivitas multimedia PowerPoint interaktif pertumbuhan dan perkembangan selada (Lactuca sativa L.) dalam hidroponik rakit apung sebagai media pembelajaran pada materi pertumbuhan dan perkembangan tumbuhan di kelas XII SMA. [Skripsi, Universitas Tanjungpura, Pontianak]

Purbajanti, E. D., Slamet, W., \& Kusmiyati, F. (2017). Hydroponic bertanam tanpa tanah. Semarang: EF Press Gigimedia. 
The application of sustainable organic farming with hydroponic system for farmers in Gending Village Ihyak Mustofa, Mas Ahmad Baihaqi, Zico Awalatul Badar

Rofiq, M. (2019, Januari 16). 60\% lahan jagung di Probolinggo alih fungsi, hasil panen mencukupi. Detik.com.

Roidah, I. S. (2014). Pemanfaatan lahan kosong dengan menggunakan sistem hidroponik. Bonorowo: Jurnal Universitas Tulungagung, 1(2), 43-49. https://doi.org/10.36563/bonorowo.v1i2.14

Singgih, M., Prabawati, K., \& Abdulloh, D. (2019). Bercocok tanam mudah dengan sistem hidroponik NFT. Jurnal Abdikarya: Jurnal Karya Pengabdian Dosen dan Mahasiswa, 3(1), 21-24. https://doi.org/10.30996/abdikarya.v3i1.3696

Swastika, S., Yulfida, A., \& Sumitro, Y. (2018). Buku petunjuk teknis budidaya sayuran hidroponik (bertanam tanpa media tanah). Riau: Balai Pengkajian Teknologi Pertanian (BPTP) Balitbangtan Riau, Badan Penelitian dan Pengembangan Pertanian, Kementerian Pertanian. 